\title{
Data set from shake table tests of free-standing rocking bodies
}

\section{Journal Article}

\section{Author(s):}

Vassiliou, Michalis F.; Cengiz, Cihan; Dietz, Matthew; Dihoru, Luiza; Broccardo, Marco; Mylonakis, George; Sextos, Anastasios; Stojadinovic, Bozidar (1)

Publication date:

2021-11

\section{Permanent link:}

https://doi.org/10.3929/ethz-b-000492304

\section{Rights / license:}

Creative Commons Attribution 4.0 International

\section{Originally published in:}

Earthquake Spectra 37(4), https://doi.org/10.1177/87552930211020021

\section{Funding acknowledgement:}

730900 - Seismology and Earthquake Engineering Research Infrastructure Alliance for Europe (EC) 


\section{Data set from shake table tests of free-standing rocking bodies}

Earthquake Spectra

$1-17$

(C) The Author(s) 2021

(c) $(i)$

Article reuse guidelines: sagepub.com/journals-permissions DOI: 10.1 I 777/875529302। I02002।

journals.sagepub.com/home/eqs

\author{
Michalis F Vassiliou, EERI' ${ }^{1}$, Cihan Cengiz ${ }^{2}(\mathbb{D}$, \\ Matt Dietz ${ }^{2}$, Luiza Dihoru ${ }^{2}$, Marco Broccardo ${ }^{3}$ (D), \\ George Mylonakis, EERI ${ }^{2,4,5}{ }^{(D}$, Anastasios \\ Sextos, EERI ${ }^{2}$, and Bozidar Stojadinovic, EERI'
}

\begin{abstract}
In earthquake engineering, structural models are validated by performing a time history analysis and comparing its maximum to the maximum response obtained by a shake table test. It has been shown that this is a sufficient (but not a necessary) precondition to accept a numerical model. Numerical models can fail to predict the planar rocking response of a rigid block, but may succeed in predicting the statistics of the response to an ensemble of ground motions. As seismic response is inherently stochastic, comparison of the statistics of the numerically simulated response to the statistics of the experimentally obtained benchmark response for the same ensemble of earthquake excitation is a sufficient (and easier to pass) model validation test. This article describes the publicly available data of a set of 12 free rocking vibration and II 5 shake table tests of six three-dimensional rocking and sliding columns, designed at ETH Zurich and performed at EQUALS Laboratory, University of Bristol. The data can be used to statistically validate different approaches that aim to model threedimensional rocking structures.
\end{abstract}

\title{
Keywords
}

rocking, uplifting structures, statistical model validation, shake table testing, seismic behavior of equipment

Date received: 5 February 202I; accepted: 5 May 202I

\footnotetext{
'Department of Civil, Environmental, and Geomatic Engineering, ETH Zurich, Zurich, Switzerland

${ }^{2}$ Department of Civil Engineering, University of Bristol, Bristol, UK

${ }^{3}$ University of Trento, Trento, Italy

${ }^{4}$ Department of Civil \& Infrastructure Engineering, Khalifa University, Abu Dhabi, United Arab Emirates

${ }^{5}$ University of California, Los Angeles (UCLA), Los Angeles, CA, USA
}

Corresponding author:

Michalis F Vassiliou, Department of Civil, Environmental, and Geomatic Engineering, ETH Zurich, Stefano Francini Platz 5, 8093, Zurich, Switzerland.

Email: vassiliou@ibk.baug.ethz.ch 


\section{Introduction}

Rocking structures are not fixed to the ground, but can uplift and sustain a strongly nonlinear motion. It has been suggested that this uplift can be used as a form of seismic isolation (sometimes referred to as "rocking isolation") for both buildings (Bachmann, 2018; Bachmann et al., 2018b, 2019; Cherepinskiy, 2004; Ríos-García and Benavent-Climent, 2020; Uzdin et al., 2009) and bridges (Agalianos et al., 2017; Dimitrakopoulos and Giouvanidis, 2015; Kashani et al., 2018; Makris and Vassiliou, 2013; Reggiani Manzo and Vassiliou, 2021; Sideris et al., 2014; Thiers-Moggia and Málaga-Chuquitaype, 2020; Vassiliou, 2018; Vassiliou et al., 2017). However, until recently, it was believed that rocking motion is unpredictable by analytical or numerical models, because numerical models often failed to reproduce the experimental data available in the literature (Aslam et al., 1980; Drosos and Anastasopoulos, 2014; ElGawady et al., 2011; Kalliontzis and Sritharan, 2018; Lipscombe and Pellegrino, 1993; Ma, 2010; Mouzakis et al., 2002; Peña et al., 2007; Priestley et al., 1978), especially when it comes to seismic response. Even worse, shake table tests of rocking systems have often proven to be non-repeatable (Anagnostopoulos et al., 2019; Bachmann et al., 2018a). The seismic behavior of non-structural elements and equipment (Bao and Konstantinidis, 2020; Dar et al., 2016, 2018; Di Egidio et al., 2015; Di Sarno et al., 2019; Konstantinidis and Makris, 2010; Sextos et al., 2017; Voyagaki et al., 2018; Wittich and Hutchinson, 2015) frequently involves three-dimensional rocking with slidinga behavior which is even harder to predict than planar rocking. Thus, to further evaluate their seismic behavior, it is necessary to develop three-dimensional rocking models.

Validation of such strongly non-linear models is a challenging task. Bachmann et al. (2018a) and Del Giudice et al. (2020) have suggested that validation of numerical models in earthquake engineering should be performed statistically. That is, it should require that the model is able to predict a statistical measure of the temporal maxima of the responses to a set of ground motions, for example, their Cumulative Distribution Function (CDF). Predicting the response to each excitation is desirable but not necessary. This is a weaker validation procedure but still suffices for the scope of earthquake engineering, given its inherently stochastic nature. In fact, for tests that are not repeatable, this is the only possible way that numerical models can be validated.

This data article contains the results of multiple shake table tests of free-standing rocking bodies designed at ETH Zurich and fabricated at the University of Bristol. The tests were carried out at the Earthquake and Large Structures Laboratory (EQUALS) of the University of Bristol and were funded by the research project "Statistical verification and validation of $3 \mathrm{D}$ seismic rocking motion models (3DROCK)." The project was selected for the Transnational Access part of the ERC Horizon 2020 project SERA. This article presents the data of the conducted tests. The data can be used for the statistical validation of numerical models of the seismic response of free-standing rocking bodies, and complements corresponding data for a wobbling podium structure. The latter is a structure that is allowed to uplift and rock along different directions on horizontal plane, but mechanically restrained not to step out of its original position (Vassiliou et al., 2021a). Given the extent of the tests performed and the breadth of the response quantities monitored, it is deemed that this data set consists a useful and well-documented contribution for future validation of numerical models as it is discussed in the following.

\section{Description of the specimens}

First, it is important to clarify that the intention of the rocking specimens was not to represent a specific free-standing rocking structure or equipment, but to serve as a benchmark 


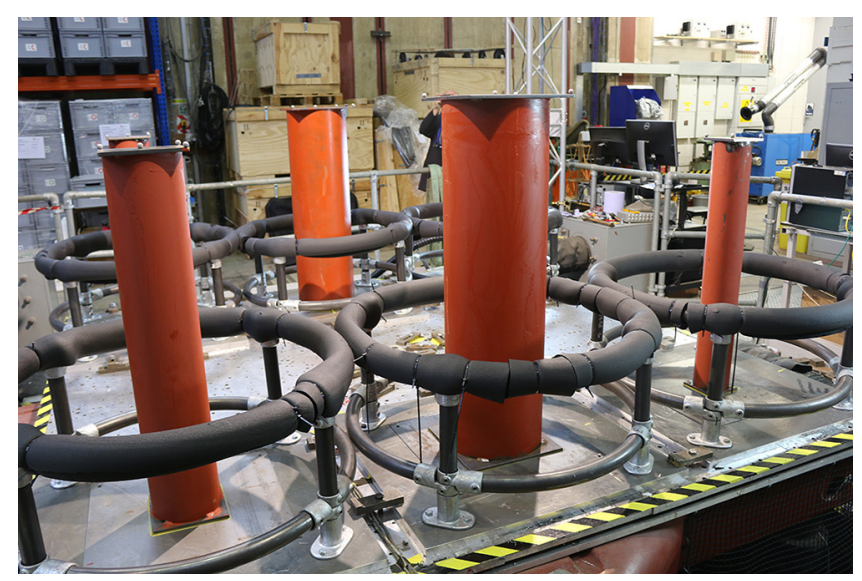

Figure I. Free-standing rocking specimens with square bases are lined up in the front row, while those with round bases are aligned in the back row.

for validation of numerical models for predicting the seismic response of a class of freestanding rocking bodies. In order for the specimens to serve this purpose, they had to fulfill two fundamental design criteria: (a) remain elastic and not accumulate damage in order to enable statistical validation; and (b) be easy to re-set after a test with or without overturning. Therefore, six free-standing column specimens of three different heights and slenderness were designed. A specimen consisted of a length of round steel pipe with a steel plate welded on top (Figures 1 and 2), both made using S275 steel with a modulus of elasticity of $210 \mathrm{GPa}$. To make sure that the columns were not oblique, their ends were machined (lathed). The top plate served as a base for attaching markers used to measure displacements. Apart from the top plate, three of the columns had a square steel plate welded at the bottom as shown in Figure 1, so that they were forced to rock on their square base, in contrast to the remaining three columns that were able to wobble on the perimeter of their circular base, deliberately machined to be flat. The bottom and top plates were equal in size and material properties. The supporting surface on the top of the shaking table was made of mild steel (material grade EN24T). The dimensions of the tested columns are presented in Figure 2. Padded frames were placed around the specimens to mitigate the risk of damage in the event of toppling (Figures 1 and 3).

\section{Warping of the square steel plates}

The $10 \mathrm{~mm}$ thickness of the square steel plates proved insufficient to prevent warping during welding. Therefore, the square-based specimens rocked on an imperfect, non-flat surface. To quantify the imperfections of the square base plates, post-test surface scans were performed using a FaroArm system. During this scanning of the specimen bases, three marker bolts were attached to the side of the plates to mark their orientation, as depicted in Figure 4.

\section{Specimen excitation}

The rocking response of the specimens was induced by a bi-directional (two orthogonal horizontal components only) dynamic excitation of its base. To this end, the specimens 

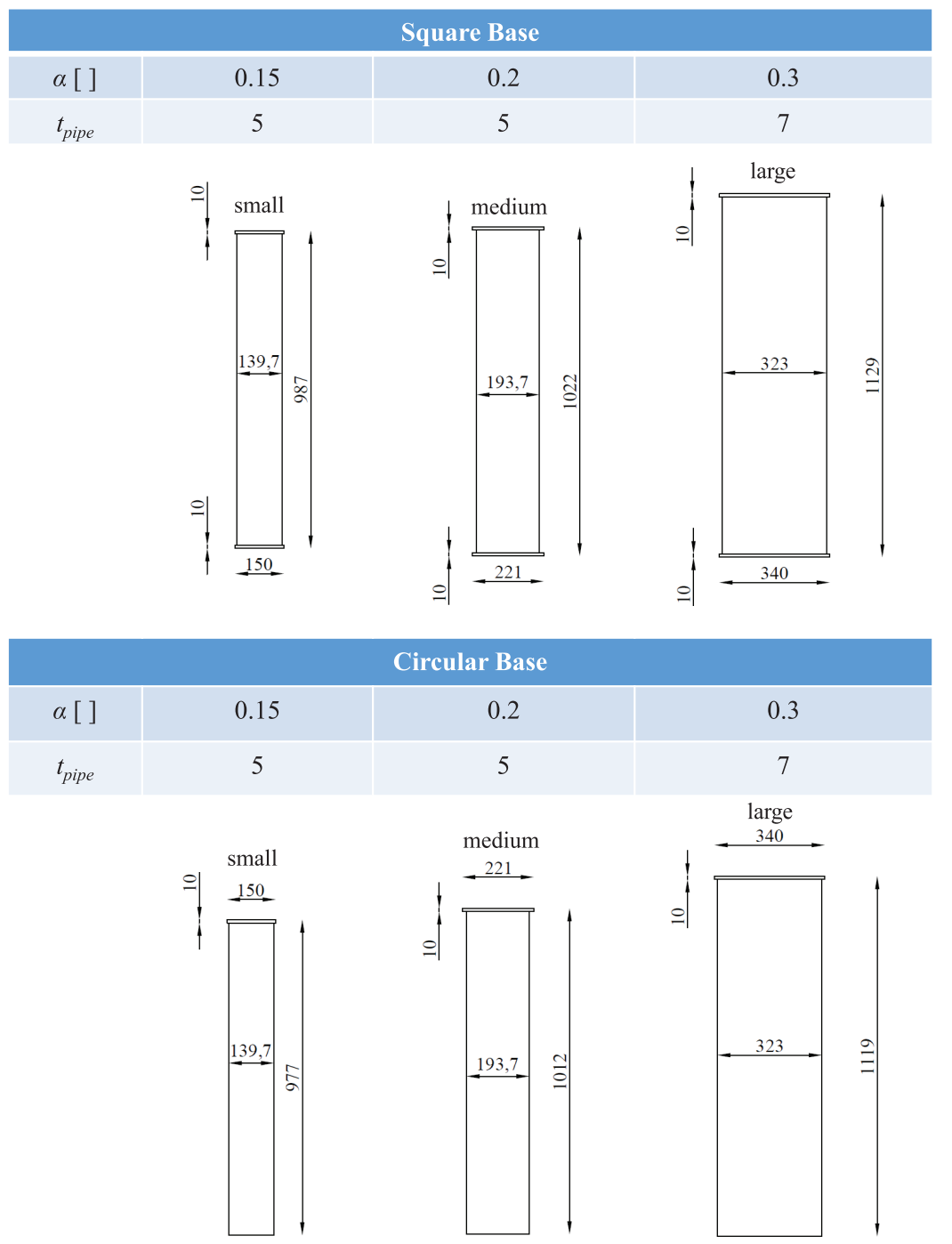

Figure 2. Dimensions (in $\mathrm{mm}$ ) of the six free-standing rocking column specimens.

were placed on the top of the 6 degree of freedom (DOF) $3 \mathrm{~m} \times 3 \mathrm{~m}$ shake table (University of Bristol, 2021). More info on the shake table can be found in Vassiliou et al. (2021b).

\section{Ground motions}

The applied ground motions were synthesized using a stochastic ground motion model (Broccardo and Dabaghi, 2017; Broccardo and Der Kiureghian, 2014; Rezaeian and Der Kiureghian, 2008). The 1989 Loma Prieta UCSC Lick Observatory ground motion record was used as a seed ground motion to generate an ensemble of 100 ground motions with compatible elastic spectra with the recorded "seed" motion. More details on the reasoning for this choice of generating ground motions can be found in Vassiliou et al. (2021b). 


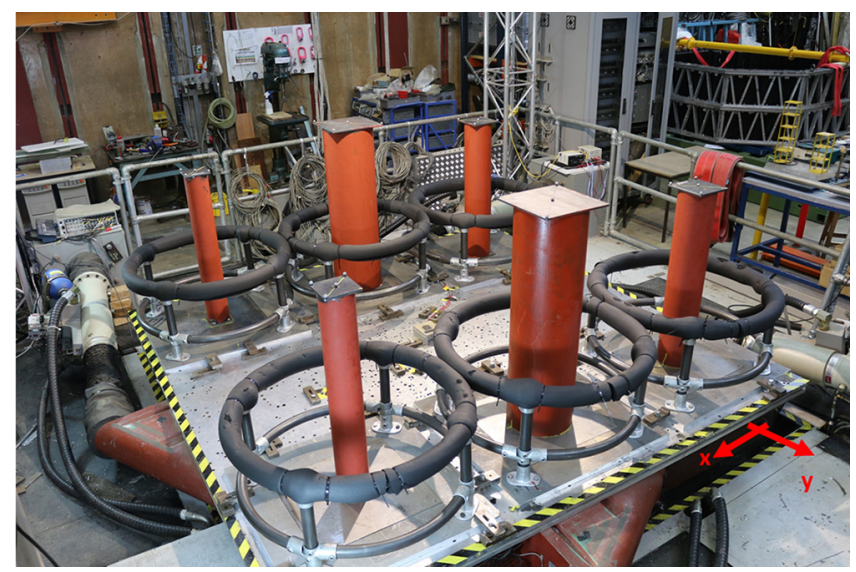

Figure 3. Free-standing rocking column specimens on the shake table at EQUALS Laboratory, University of Bristol.
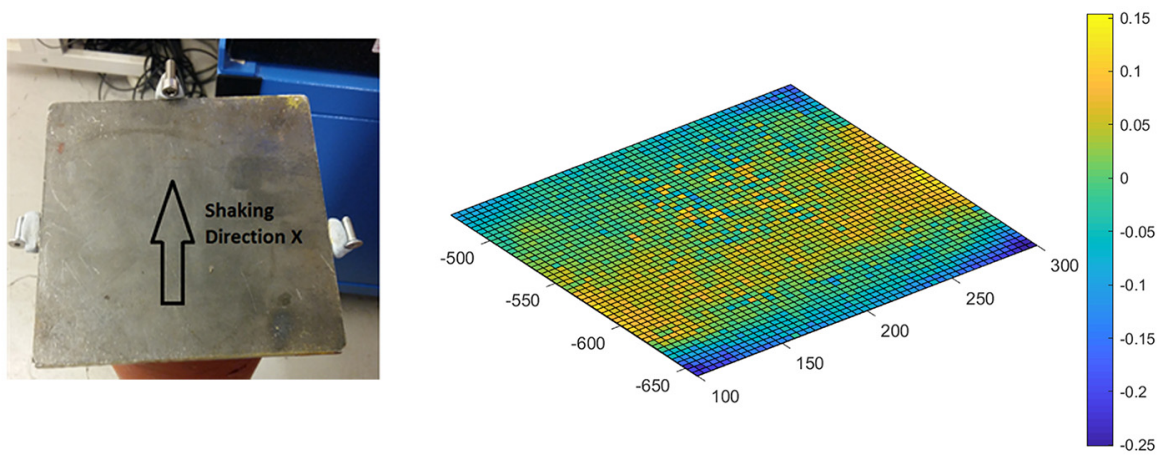

Figure 4. An imperfect square base plate, shown as it was scanned (left). Screws were mounted after the tests to indicate the orientation of the specimen on the table. Three-dimensional scan of the middlesize square column base (coordinates in $\mathrm{mm}$ ) (right).

The ensemble of the 100 synthetic ground motions was used to drive the shake table during the tests. Vertical ground motion and the three rotational excitations about the horizontal and vertical axes were not considered in this study: thus, the shaking table vertical motion and all three rotations were controlled to remain zero during the tests.

\section{Scaling of the ground motions}

In order to comply with similitude laws, time scales with the square of the length scale of the specimen (i.e., $S_{T}=\sqrt{S_{L}}$ ). The time scale of the ground motions was scaled by a factor of two, that is, the frequency of ground motions was increased by two without changing the amplitude. Therefore, at prototype scale, the free-standing rocking columns are four times larger. Detailed info about scaling in rocking problems can be found in Housner's (1963) classic paper.

Figure $5 \mathrm{e}$ and $\mathrm{f}$ plots the 5\%-damped elastic response spectra of the scaled ground motions, as they were applied by the shake table and measured using an accelerometer 
that was installed on the shaking table platform. It is worth noting, that for construction of this plot, the measured acceleration recordings offered in the data set were further processed so that a zero final velocity is enforced: This was achieved by subtracting the mean of the record from each element of that record.

It should be noted that the free-standing rocking specimens are distorted models of prototype structures because stress similitude is not preserved. This is common when similitude cannot be retained for all problem variables. Thus, parameters related to the deformability of the specimen (i.e. the material elastic modulus and the natural frequencies of the free-standing rocking columns are distorted). However, previous work (Acikgoz and DeJong, 2012; Chopra and Yim, 1985; Ma, 2010; Oliveto et al., 2003; Psycharis, 1991; Truniger et al., 2015; Vassiliou et al., 2014, 2015) suggests that the deformability of sufficiently large rocking structures does not qualitatively change their rocking behavior. Ultimately, the conducted experiments do not aim at physically modeling a prototype structure, but at creating a data set for model validation.

\section{Testing protocol}

Free vibration tests of the square based columns were performed first. The columns were manually given an initial tilt angle and released to rock freely. The tests were performed twice per direction per column resulting in $2 \times 2 \times 3=12$ tests. The positioning of the columns for these free vibration tests is given in Figure 6 (left). This resulted in tests N1N12 as shown in Table 1.

Next, the columns were placed on new positions (given in Figure 6, right) and the shake table was used to induce the 100 synthetic ground motions. Ground motion 10 was used several times to check the repeatability of the tests. This resulted in tests N24-N138 shown in Table 2. Tests N13-N23 are not reported in this article.

After each test, the column specimens were manually restored into their original position, with the same orientation. There was one exception: column $\mathrm{C} 4$ was rotated by $+90^{\circ}$ (counterclockwise) around its vertical axis after test N47 and kept in this orientation for the remaining tests (N48-N138). Since the scans of the warped square base plates were performed after all shaking table tests, the $x$ axis of the scan (see section "Warping of the square steel plates") follows from the final configuration of column $\mathrm{C} 4$, that is, the one after test N47.

\section{Instrumentation}

\section{Acceleration and position measurements}

The position of each column was tracked by installing four infrared markers on the top plate of each column (Figure 3). Four additional markers were mounted on the shake table to track its position. Therefore, there were 28 infrared markers, the numbering of which follows from Table 3. After the free vibration tests, when the columns were placed at new positions, the markers were re-mounted so that they remain roughly at their initial Cartesian coordinates. The position of the markers was tracked using a Qualisys highresolution infrared tracking system comprising five type Oqus 400 3-megapixel infrared cameras. The cameras include a near-infrared (NIR) strobe with a $30^{\circ}$ field of view and a $16 \mathrm{~mm}$ lens. 

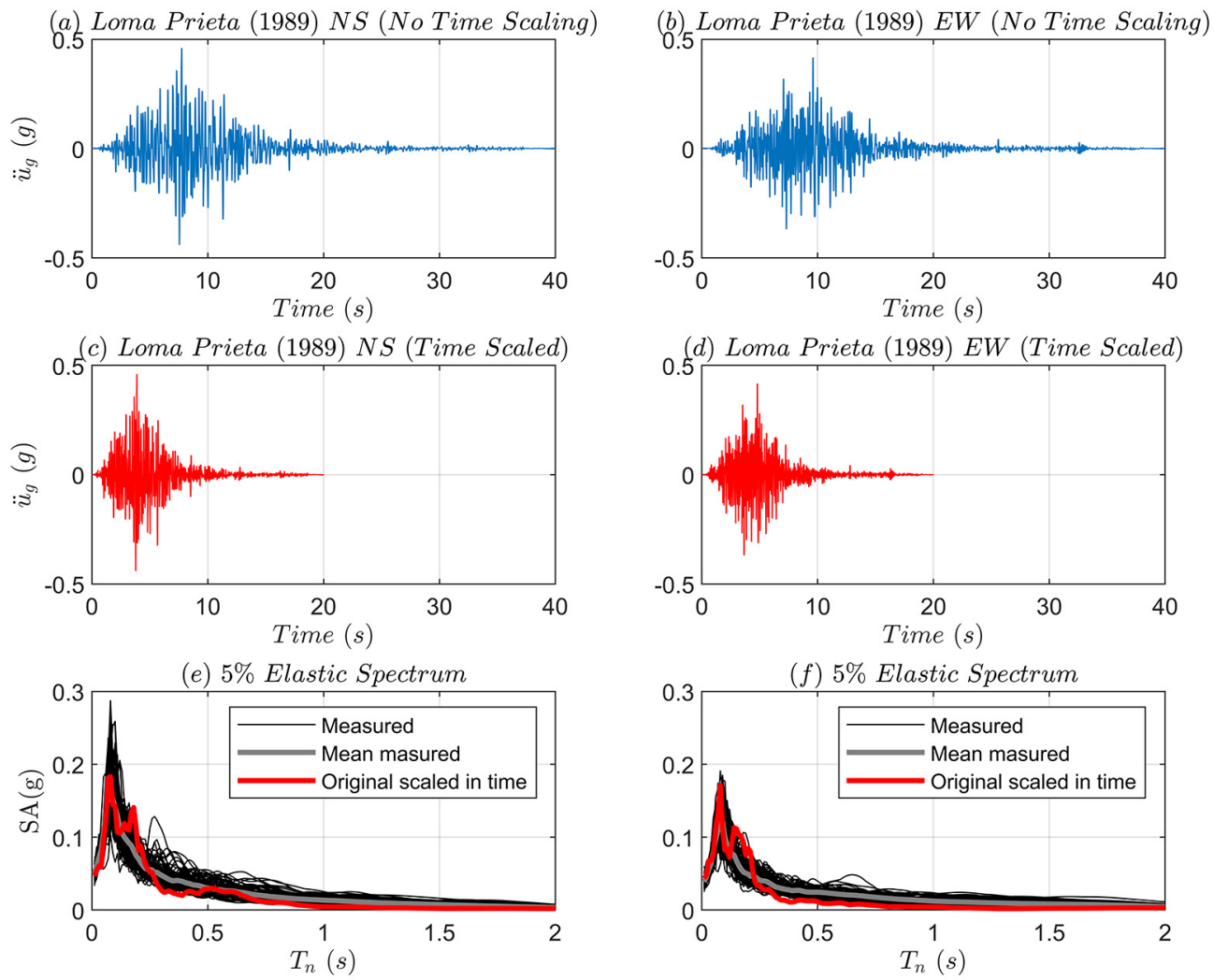

Figure 5. ( $a$ and b) 1989 Loma Prieta recorded ground motion; ( $c$ and d) Recorded ground motions scaled in time by 2; (e and $f$ ) Measured, mean measured and original ground motions $5 \%$ elastic acceleration response spectra.

Table I. List of the free vibration tests

\begin{tabular}{lll}
\hline Test no. & Direction & Column \\
\hline NI & Y & C4 \\
N2 & Y & C4 \\
N3 & $X$ & C4 \\
N4 & $X$ & $C 4$ \\
N5 & Y & C3 \\
N6 & Y & C3 \\
N7 & $X$ & $C 3$ \\
N8 & $X$ & $C 3$ \\
N9 & Y & $C 2$ \\
N10 & $Y$ & $C 2$ \\
NII & $X$ & $C 2$ \\
NI2 & $X$ & $C 2$ \\
\hline
\end{tabular}

The numbering of the columns was different in the free vibration tests (Figure 6, left) and in the shake table tests (Figure 6, right). Note that after tests N37 and N40 the markers of column C6 fell off and had to be glued again, while after test N47, the markers of 
Table 2. List of the shake table tests

\begin{tabular}{|c|c|c|c|c|c|c|c|}
\hline Test no. & Excitation & Test no & Excitation & Test no & Excitation & Test no & Excitation \\
\hline N24 & \#10 & N53 & $\# 10$ & N82 & $\# 10$ & NIII & \#76 \\
\hline N25 & \#10 & N54 & \#10 & N83 & \#5I & $\mathrm{N} I 12$ & $\# 77$ \\
\hline N26 & $\# 10$ & N55 & $\# 26$ & N84 & \#52 & NII3 & \#78 \\
\hline N27 & $\# 1$ & N56 & $\# 27$ & N85 & \#53 & NII4 & \#79 \\
\hline N28 & $\# 2$ & N57 & $\# 28$ & N86 & $\# 54$ & NII5 & \#80 \\
\hline N29 & \#3 & N58 & \#29 & N87 & \#55 & NII6 & \#81 \\
\hline N30 & $\# 4$ & N59 & $\# 30$ & N88 & $\# 56$ & NII7 & \#82 \\
\hline N3I & \#5 & N60 & \#31 & N89 & \#57 & NII8 & \#83 \\
\hline N32 & \#6 & N6I & $\# 32$ & N90 & \#58 & NII9 & \#84 \\
\hline N33 & \#7 & N62 & \#33 & N9I & \#59 & NI20 & \#85 \\
\hline N34 & $\# 8$ & N63 & \#34 & N92 & $\# 60$ & NI2I & \#86 \\
\hline N35 & \#9 & N64 & \#35 & N93 & \#6I & $\mathrm{N} 122$ & \#87 \\
\hline N36 & \#10 & N65 & $\# 36$ & N94 & \#62 & NI23 & \#88 \\
\hline N37 & \#II & N66 & \#37 & N95 & \#63 & $\mathrm{N} I 24$ & \#89 \\
\hline N38 & $\# 12$ & N67 & \#38 & N96 & \#64 & $\mathrm{N} 125$ & \#90 \\
\hline N39 & \#13 & N68 & \#39 & N97 & \#65 & NI26 & \#91 \\
\hline N40 & \#14 & N69 & $\# 40$ & N98 & \#66 & NI27 & \#92 \\
\hline N4I & $\# 15$ & N70 & $\# 41$ & N99 & \#67 & NI28 & \#93 \\
\hline N42 & \#16 & N7I & $\# 42$ & N100 & \#68 & NI29 & \#94 \\
\hline N43 & \#17 & N72 & $\# 43$ & NIOI & \#69 & NI30 & \#95 \\
\hline N44 & \#18 & N73 & \#44 & $\mathrm{N} 102$ & \#70 & NI3I & \#96 \\
\hline N45 & \#19 & N74 & $\# 45$ & $\mathrm{~N} 103$ & \#7I & NI32 & \#97 \\
\hline N46 & \#20 & N75 & $\# 46$ & NI04 & \#72 & NI33 & \#98 \\
\hline N47 & \#2I & N76 & \#47 & N105 & \#73 & NI34 & \#99 \\
\hline N48 & $\# 22$ & N77 & \#48 & N106 & \#74 & NI35 & $\# 100$ \\
\hline N49 & \#23 & N78 & $\# 49$ & N107 & \#75 & NI36 & $\# 10$ \\
\hline N50 & $\# 24$ & N79 & $\# 50$ & N108 & \#10 & NI37 & \#10 \\
\hline N5I & $\# 25$ & N80 & $\# 10$ & NI09 & \#10 & NI38 & $\# 10$ \\
\hline N52 & \#10 & N8I & \#10 & NIIO & \#10 & & \\
\hline
\end{tabular}

Table 3. Positions of the markers

\begin{tabular}{lc}
\hline Marker number & Position \\
\hline MI-M4 & Shake table \\
M5-M8 & $\mathrm{Cl}$ \\
M9-MI2 & $\mathrm{C2}$ \\
MI3-M16 & $\mathrm{C3}$ \\
MI7-M20 & $\mathrm{C} 4$ \\
M2I-M24 & $\mathrm{C5}$ \\
M25-M28 & $\mathrm{C6}$ \\
\hline
\end{tabular}

$\mathrm{C} 4$ were rotated into new positions, as the column was rotated. The coordinate system is shown in Figure 3. The marker position sampling rate was $100 \mathrm{~Hz}$.

The horizontal components of the acceleration of the shaking table were monitored by a block of mutually orthogonal Setra 141a accelerometers at a sampling rate of $5000 \mathrm{~Hz}$. The acquired data were filtered using a low-pass eight-pole Butterworth filter with a cutoff frequency set at $1400 \mathrm{~Hz}$. The range of the accelerometers was $\pm 8 g$.

The synchronization system for the disparate acquisition systems utilizes a master crystal oscillator and a digitally programmable device that derives the DAQ clocks from this 
Positioning for free rocking vibration tests

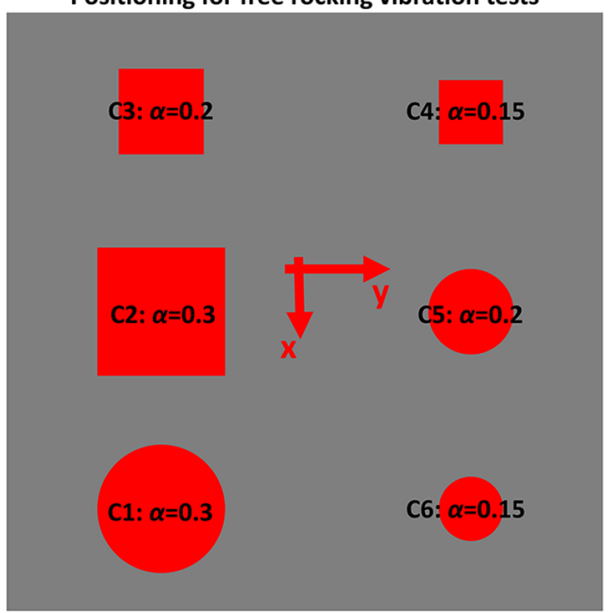

Positioning for shake table excitation

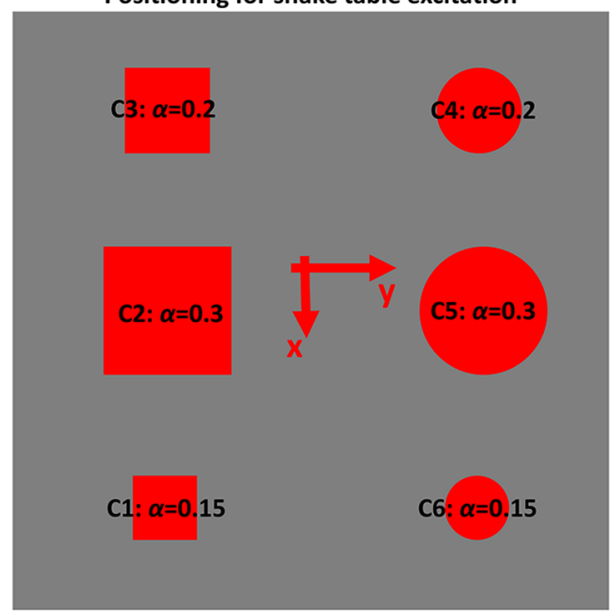

Figure 6. Positions of the free-standing rocking column specimens for the free rocking vibration tests (left) and the shake table excitation tests (right).

master. When triggered, the synchronization system commences with a rising edge simultaneously on each clock output and maintains synchronization thereafter. The clocks are integer multiples $(5000$ and $100 \mathrm{~Hz}$ ), so every 50 cycles of the high-rate clock for the DAQ system, the two systems will have coincident rising edge clocks.

\section{Photos and video recordings}

Photos of the specimen were taken before, in between and after the tests, so that any potential damage caused by uplifting, minor sliding, and impact of the specimens is recorded. Videos of several of the tests were made.

\section{Test observations}

The free rocking vibration tests showed that there was out-of-plane motion due to imperfections, especially for the $\alpha=0.15$ and $\alpha=0.20$ specimens.

The specimens suffered no damage during the tests. The imperfections of the squarebased specimens caused them to uplift more easily and to exhibit less impact damping, because they were not rocking on the perimeter of their bases, but on the intermediate points.

\section{Test data}

\section{Data organization}

The test data are publicly available at ETH Research Collection platform (Vassiliou et al., 2020), where there are indefinitely maintained. The dataset comprises five files compressed using the ZIP format, containing (a) the measurements of the position of the markers (from which the displacements relative to the laboratory strong floor can be computed), (b) the acceleration measurements, (c) the surface scans of the base plates, (d) the test 


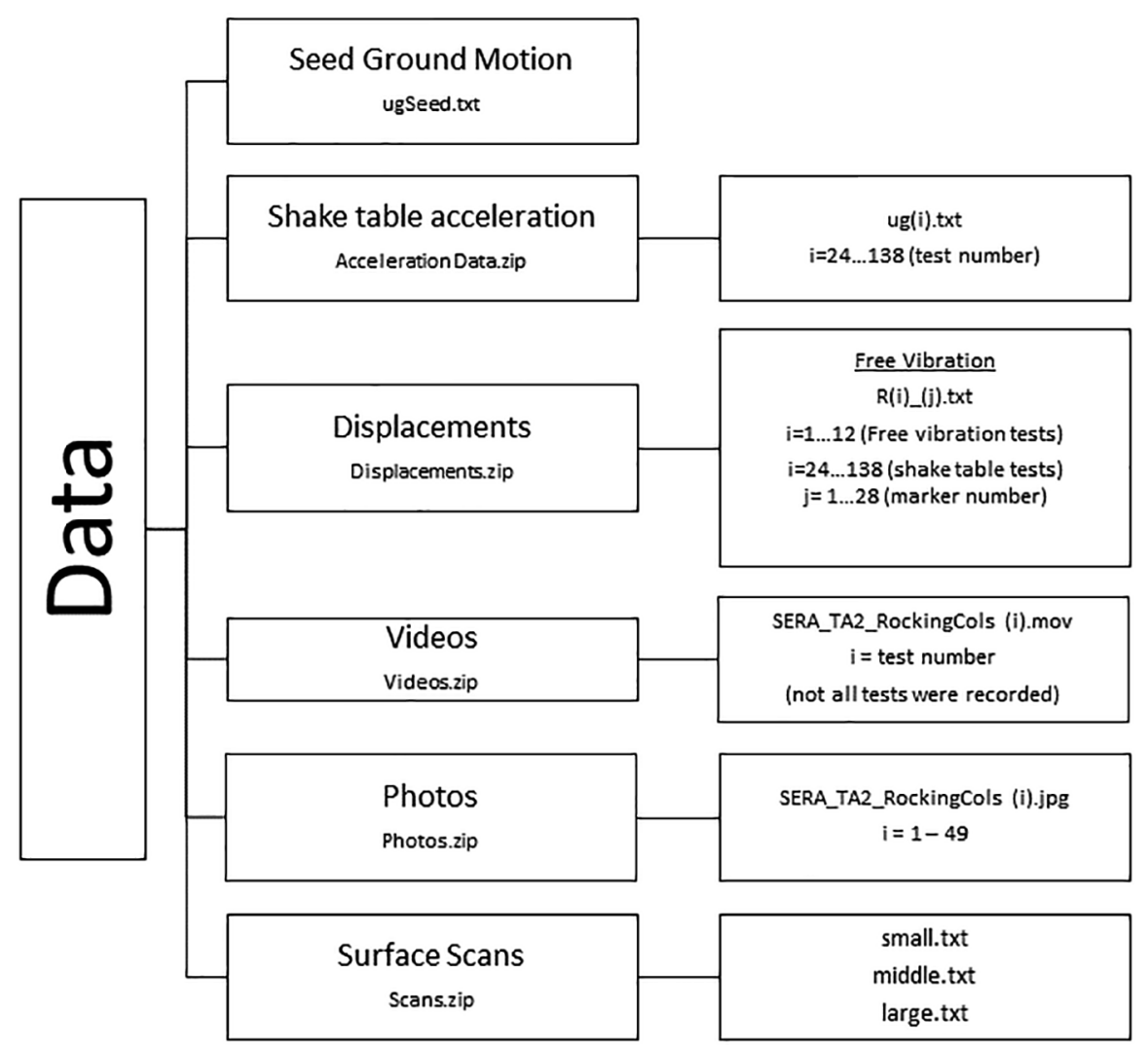

Figure 7. Data organization.

videos, and (e) photos of the specimens. The structure of the data files is summarized in Figure 7.

\section{Displacement data}

The time histories of the marker positions are provided as ASCII files. The files are named Rij.txt, and each one comprises three columns, corresponding to the position of the marker along the $x, y$, and $z$ directions (in millimeters). The coordinate system is shown in Figure 3 . The table platen is horizontal and lies in the $x-y$ plane of this coordinate system. Index $i$ denotes the test number. It runs from 1 to 12 for the free vibration tests and from 24 to 138 for the shake table tests - tests N13 to N23 are not reported herein. Index $j$ denotes the marker/target number: The markers placed on the shake table are $j=1-4$, while markers $j=5-28$ are placed on the top plates of each column (Figure 3). The data are sampled at $100 \mathrm{~Hz}$ and processed by the Qualisys system.

\section{Acceleration data}

The filtered acceleration time history records from 115 tests are provided as ASCII files named ugi.txt, where $i=$ \{test number\}. Within each file, the first and second columns are the accelerations in the $x$ and $y$ directions in units of the acceleration of gravity $g$. The 
original "seed" ground motion that was used to synthesize the motions is also provided as file "ugOriginal.txt." Its first column is the time, the second and third are the $x$ and $y$ accelerations in units of $g$.

\section{Surface scans}

The surface scans of the warped base plates of the square-based specimens are provided as .txt files. The files are named "small," "medium," and "large" in accordance with the size of the plates attached to the ends of the pipe sections of the specimens. Each file contains three columns corresponding to the local Cartesian coordinates (in millimeters) of the points of the surface scan. The $x$ axis of the local scanner coordinate system is parallel to the global $x$ axis and it has the same direction (sign). The global coordinate Cartesian system is shown in Figure 3.

\section{Derived data examples}

Throughout this section, the displacement of the table was derived based on the displacement of Marker M1. This should theoretically be equal to the displacements of markers M2-M4, as no rotations were applied to the shake table. However, small deviations between the displacements of markers M1 and M4 were recorded, because the table did unavoidably experience some small rotations.

Figure 8 plots the displacement of the top of the square-based columns $\mathrm{C} 4, \mathrm{C} 3$, and $\mathrm{C} 2$ during free rocking vibration tests N1, N5, and N9, respectively. More specifically, the displacements of the markers mounted at the center of the square plate on top of these columns are plotted. Note that the displacement is computed as the relative position with respect to the position at time instant $t=0$. As the position recording started during the manual uplift (tilting) of the columns (and not before it), the columns were not necessarily vertical at $t=0$.
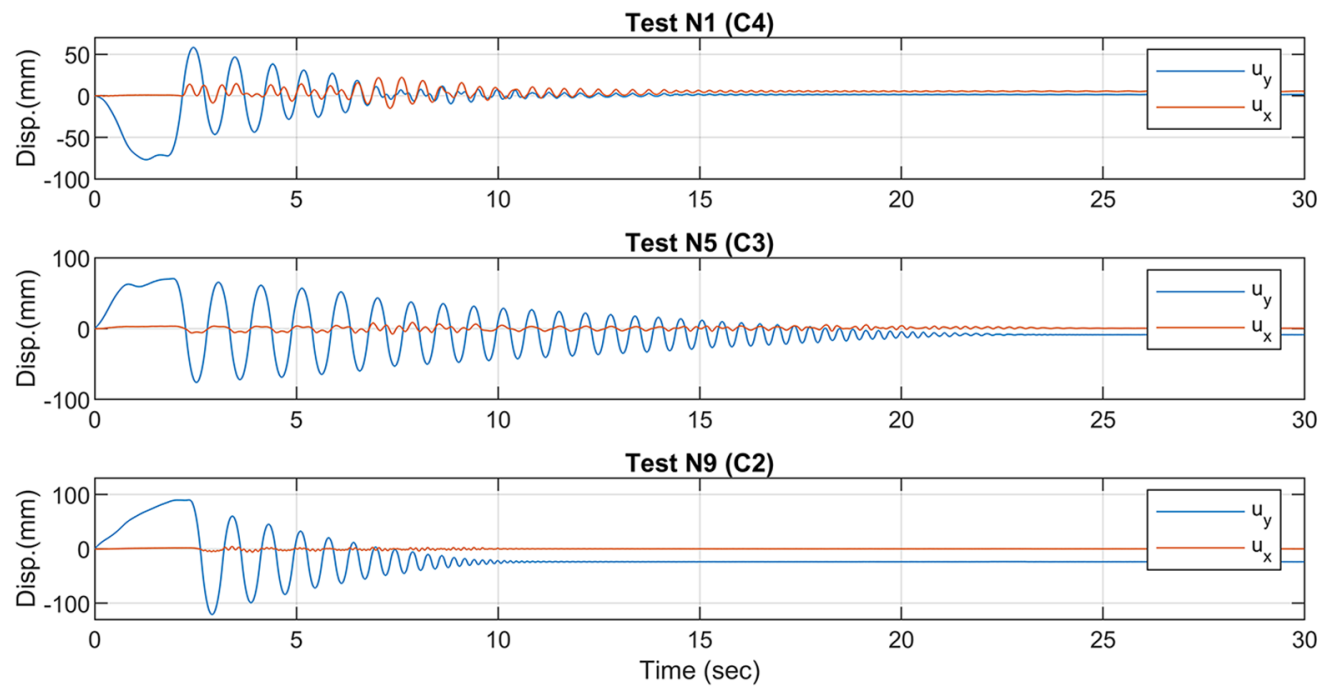

Figure 8. Response history of the displacements at the top of the columns $\mathrm{C} 4, \mathrm{C} 3$, and $\mathrm{C} 2$ for free vibration tests $\mathrm{NI}, \mathrm{N} 5$, and $\mathrm{N} 9$, respectively. 

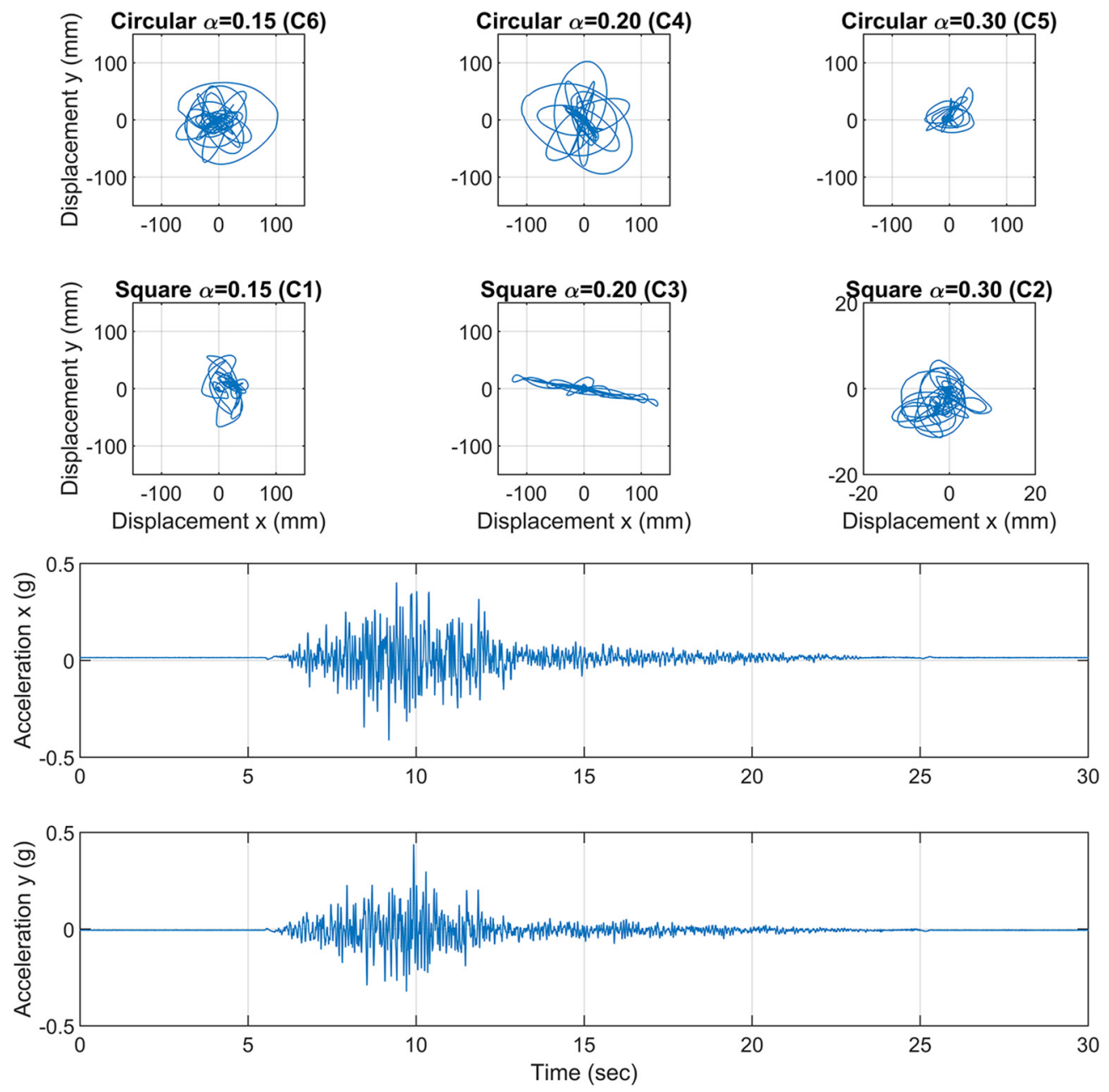

Figure 9. Test N40. Horizontal displacement orbit plots of the top middle markers on all six columns (top two rows) and recorded shake table acceleration (bottom two rows).

Figure 9 plots the orbits of the horizontal displacements of the marker at the top-center position for all six specimens during test N40. It also plots the two horizontal components of the acceleration, as recorded and filtered with a low-pass filter (but without correcting them for non-zero mean).

Figure 10 plots the outcomes of three repeatability tests (N52-N54). In general, repeatability is not observed.

\section{Data use}

As stated previously, the main purpose of the generated dataset is to allow for the validation of numerical and analytical models for seismic response of three-dimensional uplifting structures that rock and slide without any constraints. Improving these models will reduce 

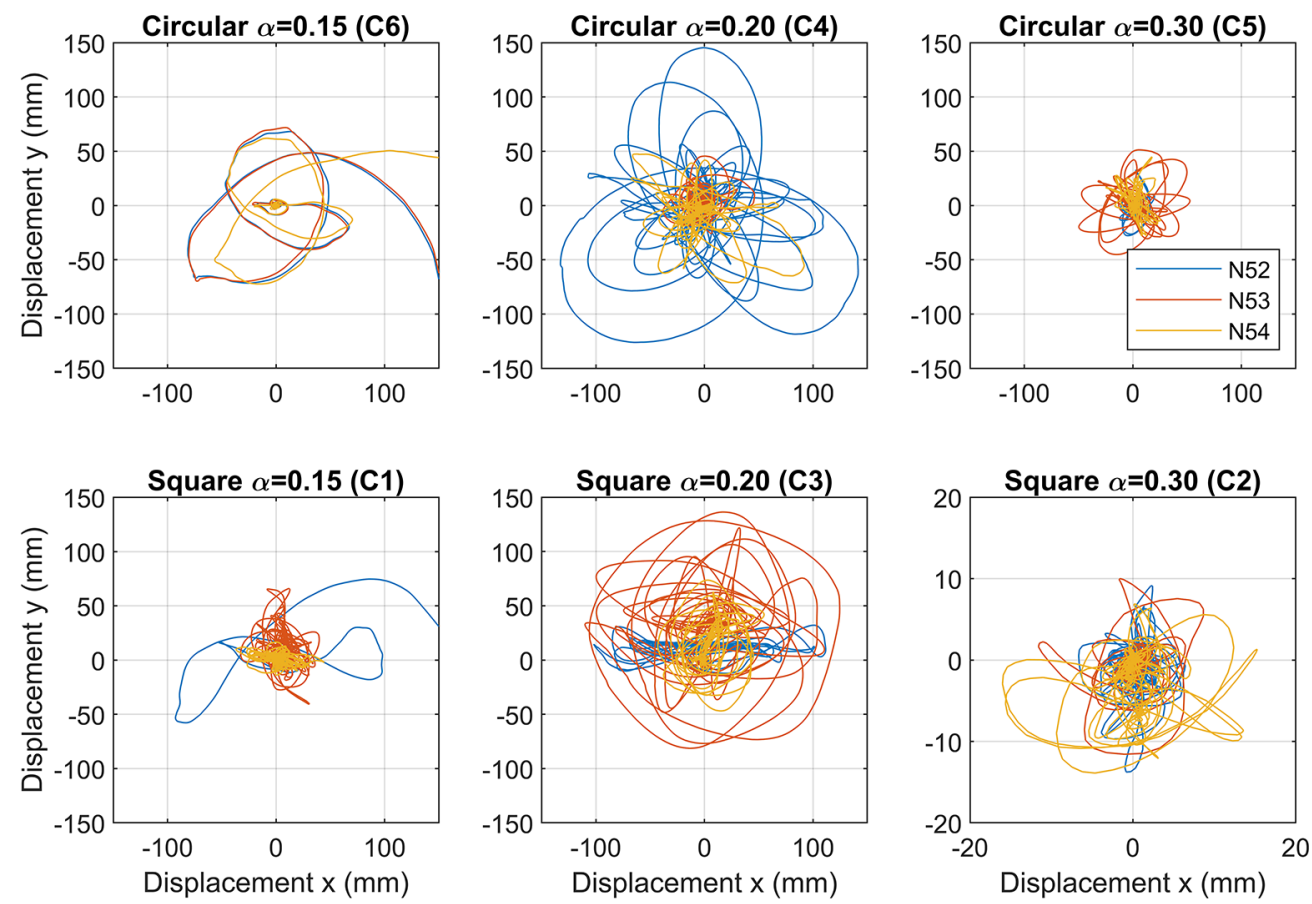

Figure 10. Repeatability test for excitation \#10 (tests N52, N53, and N54): Orbits of the horizontal displacements of the top middle markers on all six columns.

the epistemic uncertainty and will enable the better prediction of the response of rocking objects, as well as allow for a better understanding of the seismic behavior of unanchored equipment, museum artifacts, and statues.

As the specimens remain undamaged during the tests, it was possible to perform multiple shake table tests, as the concept of statistical model validation (Bachmann et al., 2018a) suggests. Models can be validated in terms of their ability to predict the statistics of the response to a set of ground motions, rather than the response to individual excitations. This concept was adopted in the PEER 2019 blind prediction contest (Vassiliou et al., 2021a) that involved a wobbling podium structure allowed to uplift, but not to step out of its initial position (Vassiliou et al., 2021b). That contest showed that both finite element method (FEM) and discrete element method (DEM) models can predict the statistics of the response, even though they fail to predict responses to individual records with a reasonable accuracy. Hence, the data presented herein can be used to compare modeling approaches (e.g. FEM models, DEM models, analytical models based on flexible or rigid rocking body assumptions) and to determine the relative importance of the different parameters used in each of these approaches.

\section{Conclusion}

This article presents the publicly available data obtained from a series of 12 free rocking vibration and 115 shake table tests on six different free-standing rocking columns. The specimens, designed at ETH Zurich and fabricated at the University of Bristol, represent 
rigid objects allowed to slide and rock freely. The tests were performed at the EQUALS Laboratory, University of Bristol. The purpose of the data at hand is to serve as a benchmark response data set for the statistical validation of numerical models used to predict the seismic response of rocking and sliding structures. The authors hope this will lead to a more accurate prediction of the seismic response of unanchored equipment and other rocking objects.

\section{Acknowledgments}

The authors acknowledge the contribution of the personnel at EQUALS, University of Bristol.

\section{Declaration of conflicting interests}

The author(s) declared no potential conflicts of interest with respect to the research, authorship, and/ or publication of this article.

\section{Funding}

The author(s) disclosed receipt of the following financial support for the research, authorship, and/ or publication of this article: This research was conducted as part of the transnational access project "Statistical verification and validation of 3D seismic rocking motion models (3DROCK)" funded by the EC H2020 under grant agreement number 730900 with Bozidar Stojadinovic as PI for the ETH Zurich, Marco Broccardo and Michalis Vassiliou as co-PIs from the ETH Zurich, and George Mylonakis as PI for University of Bristol (SERA: Seismology and Earthquake Engineering Research Infrastructure Alliance for Europe, http://www.sera-eu.org/).

\section{ORCID iDs}

Michalis F Vassiliou (D) https://orcid.org/0000-0002-4590-2126

Cihan Cengiz (iD https://orcid.org/0000-0002-9475-8124

Marco Broccardo (iD https://orcid.org/0000-0003-4058-260X

George Mylonakis (iD https://orcid.org/0000-0002-8455-8946

Anastasios Sextos (D) https://orcid.org/0000-0002-2616-9395

Bozidar Stojadinovic (iD https://orcid.org/0000-0002-1713-1977

\section{References}

Acikgoz S and DeJong MJ (2012) The interaction of elasticity and rocking in flexible structures allowed to uplift. Earthquake Engineering \& Structural Dynamics 41(15): 2177-2194.

Agalianos A, Psychari A, Vassiliou MF, Stojadinovic B and Anastasopoulos I (2017) Comparative assessment of two rocking isolation techniques for a motorway overpass bridge. Frontiers in Built Environment 3: 47.

Anagnostopoulos S, Norman J and Mylonakis G (2019) Fractal like overturning maps for stacked rocking blocks with numerical and experimental validation. Soil Dynamics \& Earthquake Engineering 125: 105659.

Aslam M, Salise DT and Godden WG (1980) Earthquake rocking response of rigid bodies. Journal of the Structural Division 106(2): 377-392.

Bachmann JA (2018) Development of self-centering systems with geometry-controlled stiffness for earthquake hazard mitigation. PhD Thesis, ETH Zurich, Zurich.

Bachmann JA, Strand M, Vassiliou MF, Broccardo M and Stojadinović B (2018a) Is rocking motion predictable? Earthquake Engineering \& Structural Dynamics 47(2): 535-552.

Bachmann JA, Vassiliou MF and Stojadinović B (2018b) Dynamics of rocking podium structures. Earthquake Engineering \& Structural Dynamics 46(14): 2499-2517. 
Bachmann JA, Vassiliou MF and Stojadinovic B (2019) Rolling and rocking of rigid uplifting structures. Earthquake Engineering \& Structural Dynamics 48(14): 1556-1574.

Bao Y and Konstantinidis D (2020) Dynamics of a sliding-rocking block considering impact with an adjacent wall. Earthquake Engineering \& Structural Dynamics 49(5): 498-523.

Broccardo M and Dabaghi M (2017) A spectral-based stochastic ground motion model with a nonparametric time-modulating function. In: Proceedings of the 12th international conference on structural safety and reliability, Vienna, 6-17 August.

Broccardo M and Der Kiureghian A (2014) Simulation of near-fault ground motions using frequency-domain discretization. In: Proceedings of the 10th NCEE, Anchorage, AL, 21-25 July.

Cherepinskiy Y (2004) Seismic isolation of buildings with application of the kinematics bases. In: Proceedings of the 13th world conference on earthquake engineering, Vancouver, BC, Canada, 1-6 August.

Chopra AK and Yim SCS (1985) Simplified earthquake analysis of structures with foundation uplift. Journal of Structural Engineering 111(4): 906-930.

Dar A, Konstantinidis D and El-Dakhakhni WW (2016) Evaluation of ASCE 43-05 seismic design criteria for rocking objects in nuclear facilities. Journal of Structural Engineering 142(11): 04016110.

Dar A, Konstantinidis D and El-Dakhakhni WW (2018) Seismic response of rocking frames with top support eccentricity. Earthquake Engineering \& Structural Dynamics 47(12): 2496-2518.

Del Giudice L, Wrobel R, Leinenbach C and Vassiliou MF (2020) Static testing of additively manufactured microreinforced concrete specimens for statistical structural model validation at a small scale. In: Proceedings of the 8th international conference on advances in experimental structural engineering (8AESE), Christchurch, New Zealand, 3-5 February.

Di Egidio A, Alaggio R, Contento A, Tursini M and Della Loggia E (2015) Experimental characterization of the overturning of three-dimensional square based rigid block. International Journal of Non-Linear Mechanics 69: 137-145.

Di Sarno L, Magliulo G, D'Angela D and Cosenza E (2019) Experimental assessment of the seismic performance of hospital cabinets using shake table testing. Earthquake Engineering \& Structural Dynamics 48(1): 103-123.

Dimitrakopoulos EG and Giouvanidis AI (2015) Seismic response analysis of the planar rocking frame. Journal of Engineering Mechanics 141(7): 04015003.

Drosos V and Anastasopoulos I (2014) Shaking table testing of multidrum columns and portals. Earthquake Engineering and Structural Dynamics 43(11): 1703-1723.

ElGawady MA, Ma Q, Butterworth JW and Ingham J (2011) Effects of interface material on the performance of free rocking blocks. Earthquake Engineering \& Structural Dynamics 40(4): 375-392.

Housner GW (1963) The behavior of inverted pendulum structures during earthquakes. Bulletin of the Seismological Society of America 53(2): 403-417.

Kalliontzis D and Sritharan S (2018) Characterizing dynamic decay of motion of free-standing rocking members. Earthquake Spectra 34(2): 843-866.

Kashani MM, Gonzalez-Buelga A, Thayalan RP, Thomas AR and Alexander NA (2018) Experimental investigation of a novel class of self-centring spinal rocking column. Journal of Sound and Vibration 437: 308-324.

Konstantinidis D and Makris N (2010) Experimental and analytical studies on the response of 1/4scale models of freestanding laboratory equipment subjected to strong earthquake shaking. Bulletin of Earthquake Engineering 8(6): 1457-1477.

Lipscombe PR and Pellegrino S (1993) Free rocking of prismatic blocks. Journal of Engineering Mechanics 119(7): 1387-1410.

Ma QTM (2010) The mechanics of rocking structures subjected to ground motion. PhD Thesis, ResearchSpace@, Auckland, Auckland, New Zealand.

Makris N and Vassiliou MF (2013) Planar rocking response and stability analysis of an array of free standing columns capped with a freely supported rigid beam. Earthquake Engineering \& Structural Dynamics 42(3): 431-449. 
Mouzakis HP, Psycharis IN, Papastamatiou DY, Carydis PG, Papantonopoulos C and Zambas C (2002) Experimental investigation of the earthquake response of a model of a marble classical column. Earthquake Engineering \& Structural Dynamics 31(9): 1681-1698.

Oliveto G, Caliò I and Greco A (2003) Large displacement behaviour of a structural model with foundation uplift under impulsive and earthquake excitations. Earthquake Engineering \& Structural Dynamics 32(3): 369-393.

Peña F, Prieto F, Lourenço PB, Campos Costa A and Lemos JV (2007) On the dynamics of rocking motion of single rigid-block structures. Earthquake Engineering \& Structural Dynamics 36(15): 2383-2399.

Priestley MJN, Evison RJ and Carr AJ (1978) Seismic response of structures free to rock on their foundations. Bulletin of the New Zealand Society for Earthquake Engineering 11(3): 141-150.

Psycharis IN (1991) Effect of base uplift on dynamic response of SDOF structures. Journal of Structural Engineering 117(3): 733-754.

Reggiani Manzo N and Vassiliou MF (2021) Simplified analysis of bilinear elastic systems exhibiting negative stiffness behavior. Earthquake Engineering \& Structural Dynamics 50: 3347.

Rezaeian S and Der Kiureghian A (2008) A stochastic ground motion model with separable temporal and spectral nonstationarities. Earthquake Engineering \& Structural Dynamics 37(13): $1565-1584$.

Ríos-García G and Benavent-Climent A (2020) New rocking column with control of negative stiffness displacement range and its application to RC frames. Engineering Structures 206: 110133.

Sextos AG, Manolis GD, Ioannidis N and Athanasiou A (2017) Seismically induced uplift effects on nuclear power plants - Part 2: Demand on internal equipment. Nuclear Engineering and Design 318: 288-296.

Sideris P, Aref AJ and Filiatrault A (2014) Large-scale seismic testing of a hybrid sliding-rocking posttensioned segmental bridge system. Journal of Structural Engineering 140(6): 04014025.

Thiers-Moggia R and Málaga-Chuquitaype C (2020) Dynamic response of post-tensioned rocking structures with inerters. International Journal of Mechanical Sciences 187: 105927.

Truniger R, Vassiliou MF and Stojadinović B (2015) An analytical model of a deformable cantilever structure rocking on a rigid surface: Experimental validation. Earthquake Engineering \& Structural Dynamics 44(15): 2795-2815.

University of Bristol (2021) The EQUALS facility. http://www.bristol.ac.uk/engineering/facilities/ earthquake/ (accessed 29 April 2020).

Uzdin AM, Doronin FA, Davydova GV, Avidon GE and Karlina EA (2009) Performance analysis of seismic-insulating elements with negative stiffness. Soil Mechanics and Foundation Engineering 46(3): 15-21.

Vassiliou MF (2018) Seismic response of a wobbling 3D frame. Earthquake Engineering \& Structural Dynamics 47(5): 1212-1228.

Vassiliou MF, Broccardo M, Cengiz C, Dietz M, Dihoru L, Gunay S, Mosalam KM, Mylonakis G, Sextos A and Stojadinovic B (2021a) Shake table testing of a rocking podium: Results of a blind prediction contest. Earthquake Engineering \& Structural Dynamics 50(4): 1043-1062.

Vassiliou MF, Burger S, Egger M, Bachmann JA, Broccardo M and Stojadinovic B (2017) The three-dimensional behavior of inverted pendulum cylindrical structures during earthquakes. Earthquake Engineering \& Structural Dynamics 46(14): 2261-2280.

Vassiliou MF, Cengiz C, Dietz M, Dihoru L, Broccardo M, Mylonakis G, Sextos A and Stojadinovic B (2020) Dataset from the shake table tests of a free-standing rocking bodies. ETH Research Collection Platform. DOI: 10.3929/ethz-b-000462388.

Vassiliou MF, Cengiz C, Dietz M, Dihoru L, Broccardo M, Mylonakis G, Sextos A and Stojadinovic B (2021b) Dataset from the shake table tests of a rocking podium structure. Earthquake Spectra. Epub ahead of print 25 January. DOI: 10.1177/8755293020988017.

Vassiliou MF, Mackie KR and Stojadinović B (2014) Dynamic response analysis of solitary flexible rocking bodies: Modeling and behavior under pulse-like ground excitation. Earthquake Engineering \& Structural Dynamics 43(10): 1463-1481. 
Vassiliou MF, Truniger R and Stojadinović B (2015) An analytical model of a deformable cantilever structure rocking on a rigid surface: Development and verification. Earthquake Engineering \& Structural Dynamics 44(15): 2775-2794.

Voyagaki E, Kloukinas P, Dietz M, Dihoru L, Horseman T, Oddbjornsson O and Steer A (2018) Earthquake response of a multiblock nuclear reactor graphite core: Experimental model vs simulations. Earthquake Engineering \& Structural Dynamics 47(13): 2601-2626.

Wittich CE and Hutchinson TC (2015) Shake table tests of stiff, unattached, asymmetric structures. Earthquake Engineering \& Structural Dynamics 44(14): 2425-2443. 